\title{
Psychology Inconsistence Individual Development of Teenagers
}

\author{
Mira Sadvakasovna Iskakova ${ }^{1}$, Yussubaly Nazymovich Kamalov ${ }^{1}$, Nurlybek Omarov ${ }^{1}$, Sveta Sikhimbayeva ${ }^{1}$ \& \\ Klara Begalievna Smatova ${ }^{2}$ \\ ${ }^{1}$ M. Auezov South-Kazahstan State University, Kazakhstan \\ ${ }^{2}$ Taraz State Pedagogical Institute, Tole-bi, 62, Taraz sity, Kazakhstan \\ Correspondence: Mira Sadvakasovna Iskakova, Tauke-khan str., 5, Chimkent sity, 160012, Kazakhstan.
}

Received: December 8, 2014 Accepted: February 23, 2015 Online Published: July 30, 2015

doi:10.5539/ass.v11n19p1 URL: http://dx.doi.org/10.5539/ass.v11n19p1

\begin{abstract}
This article discusses the psychological contradictions of the adolescent's personality in modern conditions. This individualization of the loss of social interest leads to selfishness. The world has changed. Today there is an others priority and ideals. We have not formed system of values yet. We have come to know teenagers personality problems, and have put into practice psychological methods. These methods investigate a contradiction of development. The findings we describe in this article. We examined the level of self-acceptance. We are conducted a study of the psychological nature of contradictions and problems in the personal development of adolescence. The hypothesis about low self-appraisal is confirmed.
\end{abstract}

Keywords: modern teenager, development, self-esteem, attitudes, anxiety, psychological problems, aggression, self-acceptance, communication skills, behavior define

\section{Introduction}

Modern teenagers stay at an intricate world. First, the pace of technological progress dictates new requirements. Secondly, a stream of information creates a lot of "noise." It deeply affects the teenager lifestyle. Third, economic crises and ecological changes also have an effect on children. They are felt hopelessness and frustration. Young people develop a sense of unconscious protest. This individualization of the loss of social interest leads to selfishness. To adolescents is difficult to find a reference point in the country, where the old values and ideals have lost. And nothing new created.

Teenager can no longer be content with family and school life. A perception of norms often causes him feeling the conflict. Society adult with its own laws attracted the child. The future of our society depends on how we can help children solve their problems.

Mental activity always gets reflected in the actions and reactions of the speech. It is important to study the mental life in the process of human activities, watching his actions, behavior. I. M. Sechenov wrote: "The human mental activity is expressed, as it is known. Mental activity is exhibiting outward signs. All people, and simple and scientists and naturalists can characterize the human by external features. (Baron \& Richardson, 2000)

In the adolescent's personality most relevant are the following contradictions:

- Between the level of mental potential of the personality of teen and the degree of its realization in activities.

- Between social motives and expectations are related to the work and not coinciding with their results.

- Between the high level of claims of great achievements and low psychological readiness for such activities.

- Between an adequate assessment of the situation and the inability of self-control.

- Between the need to predict the future course of activity and the lack of prospects for the ability

- Between the demands of modern times to an intensive work and a low culture.

Contradiction is characterized by difference and actions of the subject. More broadly, the inconsistency is not limited to the conscious action of a teenager, but any act of movement. The nature of any conflict is contained in the difference. It lies in the difference between logic and psychology of its main components. It is contained in the difference between logic and psychology of its main components. The logics and psychology on the one hand. And real activities on the other hand (Bozovic, 1968). In personality have inherent contradiction; between it's a 
stable and dynamic component. System of attitudes and behaviors is stable. But the mental attitude of the person, his current and situational components inversely are moveable.

Set of social roles of personality requires a stable, predictable behavior. Social norms and expectations of the social and psychological status of the individual, both in the primary group, and in the community are determined by frames behaviors. Checkered spiritual life of a teenager can knock it out of the primary track and put in front of an unexpected turn in life. The contradiction personality adolescent is located deep inside. It is often replaced by the experience and mood. Life orientation teenager has not been established. Its formation is associated with persistent stereotypes and little experience of life. These factors give reason to regard the person as a teenager in the social and psychological problems (Bossart, 1991).

Contradictions appear between the needs of adolescents find themselves and the difficulty of its implementation. An often obscene form of verbal communication is a means to a fuller expression of their individuality. It is both a way to "psychological discharge" from the oppressive inferiority complex.

\section{The Technique}

To study the problems and contradictions of personality development in adolescence were used following techniques (Gippenreiter, 1998):

Methodology "Identifying the level of anxiety in adolescents"

Questionnaire Eysenck.

Questionnaire Bassa-Darky.

Technique of "Scale of self."

The study was conducted in high school, age 12-15 years old subjects. The sample consisted of 100 people.

We used the technique of "Scale of anxiety." The technique is elaborated on the basis of the scale of social and situational anxiety (Kondasha, 1973; Gluhanyuk, Dyachenko, \& Semenov, 2003). Scales of the type evaluated on how a situation can cause an alarm. The advantage of the scales is, is that they allow you to identify the source of anxiety student.

Test results as described in "Identifying the level of anxiety in adolescents" have shown $34 \%$ of people had a normal level of general anxiety, and $66 \%$ higher.

We took a teenage version of the Eysenck in different classifications copyright Cattell, Leonhard, Licko (Sapagov, 2001, pp. 1-274; Dragunov, 1996). Classification depending on the ratio of the results of the scale of neuroticism and introversion. Verbal description of the characteristics of each type and the mainstream tactics, relationships with children of each type.

The results of the methodology showed that 47 teenagers inherent extraversion. They have an adequate level of self-esteem and reduced conflict. 53 teenagers have neuroticism. Consequently, they have low self-esteem and high levels of conflict. They can't decide, their own problems. Diagnosis of the aggression in adolescents conducted by the procedure compiled on the theory of A. Bass. He divided the concept of "aggression" and "hostility". He defined the latter as "a reaction to develop negative feelings and negative evaluations of people and events." In drawing up the questionnaire, we used the following principles:

Question first can belong to only one form of aggression.

Second questions formulated so as to weaken the greatest effect on the public acceptance of the answer question.

Distribution of adolescents on the scales "hostility" and "aggressiveness" showed that hostility was found in 32 adolescents and aggressiveness - at 15 in 53 teenagers a normal level of aggressiveness.

All the children, revealed the following data:

Physical aggression - 15 teenagers.

Indirect aggression - 12 teenagers.

Irritation - 9 adolescents.

Negativism - 11 teenagers.

Resentment - 19 teenagers.

Suspicion - 10 teenagers.

Verbal aggression - 20 teenagers. 
Feelings of guilt - 4 teens.

The high degree of self- acceptance and self-esteem are important for mental health and adolescent communication. So consider Rogers and some other psychologists. A high level of self-acceptance allows the child to take a good attitude on the part of others (Nemov, 2001; Krylov, 1987, p. 256; Rogov, 1996).

We carried out a test by the method of control self-teen "The scale of self".

\section{Results}

The test results showed that 20 teenagers have high level of self-acceptance. Teens in this group are self-confident. Their belief in the intrinsic value helps them communicate with new people and to deal with unexpected problems. 45 other teenagers fall into the middle group. In different situations they feel varying degrees of confidence. The degree of self-acceptance of these children will increase the rejection of unrealistic claims or improve their personal and communication skills. 25 people have are low level of self-acceptance. They are shy, insecure and do not know how to solve problems.

As a result, $53 \%$ of adolescent self-esteem is low. Also we have revealed a high level of controversy. These children are unable to solve problems on their own. $28 \%$ adolescents have anxiety in school. The communications with teachers are alarming. In $24 \%$ of adolescents self-assessment revealed anxiety. Self-concept was worrying. Also, in this group of 20 adolescents with low self-esteem and high level of verbal aggression. Verbal aggression - an expression of negative feelings through both scream, screech. Also, through the content of verbal responses - curses and threats. These children have a high level of resentment. Insult - it is envy and hatred of others for real or even fictional action. $15 \%$ of adolescents of this group are sensitive. On a scale of self-acceptance, these adolescents showed low and intermediate level. In different situations they feel varying degrees of confidence. They are not equally available to different people, characterized by shyness.

The study revealed that $47 \%$ of adolescents are extroverts. They have an adequate level of self-esteem and reduced conflict. For adolescent an aggression and anxiety, this normal. Their high level of self-acceptance helps them to communicate with new people and to deal with unexpected problems. They are confident in their own beliefs and values.

Analysis of the problem revealed problematic personality is the difficulty in the formation of self-esteem and self-acceptance. These components are responsible for the adequate assessment of the identity of their mental abilities. They are responsible for adequate correlation of claims and potential. These factors form the optimality of the chosen path and means of personal self-realization.

Adolescent's contradictions personality shows that his chief complaint is in difficult fulfillment of desires. The child begins to be aware of their role in life and the values that it needs. Teenager builds and distributes their true interests. Mental capacity of adolescents does not match his or her abilities. It is the nature of the problem of his personality. It is responsible for an adequate assessment of their mental strength and capabilities. He forms the optimality of the chosen path and means of personal self-realization.

The key to overcoming these contradictions is, first of all, an adequate representation of the adolescent's personality. This applies to the spiritual and moral potential of its scale, the possibilities and limits.

The is, important representation of the personality, with its social roles. As well, important ways to overcome intrapersonal contradictions. Also significant representation of the adequacy of role preferences and priorities for the development and implementation of their unique spiritual and mental capacities. Overcoming internal contradictions and personal consciousness involves a teenager their nature. Also, find ways to dominant values and orientations that are interconnected in a state of conflict.

In this paper, we investigate the psychology of the contradictions and problems in the personal development of adolescence.

Children with low levels of self-contradictions of adolescence tend to be more acute. Hypothesis was confirmed.

All tasks in the study were met. The purpose of the study - to study features of the contradictions of adolescence. Show the complex nature of this period and its decisive influence on the development of personality. We conducted five training sessions aimed at the removal of anxiety, aggressiveness, on the development of self-confidence and communication skills.

Also work with adolescents was conducted in individual mode, i.e. consultation.

Here we consider consultations with adolescents with emotional and volitional.

Teen 13 years old, who started to have problems with behavior. The teachers complained about, the parents 
called on the teachers' council, warned of exclusion from school. Peer relationships also deteriorated. The teenager started to behave provocatively offhand, rude, hinder teachers conduct lessons. Before that problems with study had never been. Moreover, he was very erudite boy, and his criticisms of the lessons often irritated teachers. With adolescents was conducted psycho cycle training method symbol drama (Sapagov, 2001, pp. 1-274; Nikolaenko, 1998).

At work were used as the main stage symbol drama motifs and special motifs that are recommended for work with adolescents. A sequence motif was as follows:

\section{Meadow.}

2. Creek.

3. Mount.

4. Wood.

5. The Edge of the Forest and the creature that emerges from the darkness of the forest.

\section{House.}

\section{Three trees.}

\section{The plots of land.}

Total held eight sessions lasting 40-50 minutes. Each session consisted of four stages: preliminary conversation, relaxation exercises, and view images on a given topic psychologist (motive) and their subsequent discussion. On a preliminary conversation, depending on the proposed motif covers topics about relationships with parents, classmates, and friends. Asked to think of the most memorable events of early childhood. Preliminary conversation took place for 10-15 minutes.

Relaxing by the scheme proposed by H. Leiner - the experience of warmth, heaviness and relaxation in all parts of the body. Our sessions are held in the office of psychological relief. Teen conveniently set in a chair, closed his eyes and imagined that he would like to rest a little. Submission of images lasted 15-20 minutes. Subsequent sessions began with a discussion of the image that represented the teenager in the previous lesson, and that figure, which he painted the house, depicting what appears in the image. The psychologist asked what was nice to draw and what is unpleasant; most are remembers how they have felt between sessions, and have seen a daydreams.

On the first day of class at work with meadow motif teenager presented island covered with green lush grass. He can imagining that he runs, jumps, enjoys the sun there. Then he saw on the other side of the pine forest. On a symbolic level, according to analysts, coniferous forest can be conventionally associated with masculine, paternal beginning (needle length, oblong, phallic), and deciduous forest - with the feminine, maternal beginning (leaves rounded shape).

Teen introduced that sit on the grass. The grass in the forest was stiff; there was a feeling of melancholy. Since the coniferous forest - paternal character, you can assume burdened relationship with his father. This is evident from the history: father almost did not participate in the upbringing of the child, spent much time at work, come back late, often away on business trips. In the next lesson, work was carried out with the motive stream. Teen introduced a shallow creek width of about one and a half meters of muddy, warm, sweetish taste water. It was autumn, overcast. Walk along the creek to the source is not possible. Arch of trees tightly closes the stream. Teen imagine that he went round. On the road turned a swamp, which it almost sucked. At the source of the stream was dug concrete slab. Beneath it was a pipe from which the water flowed. Wash and drink water from the source of the teenager refused. After exiting the way health teenager was not important. Since motives meadow and creek symbolize oral stage of psychosexual development, it can be assumed that in the first year of life was broken teen oral satisfaction of needs (the need for love and attention from the mother, emotional warmth, the need for breastfeeding, body contact, contact "eye to eye") and the relationship with her mother was burdened with frustrations (evidenced by the appearance of stiff grass in a meadow, a sense of longing, a source in the form of pipes, refusal to drink water from the source). Although with a history of teenage years to breastfed and up to three years before going to kindergarten, never parted with his mother, the quality of the emotional relationship with her mother, apparently, was problematic. When working with the motif of the mountain at the third session had the gently sloping hill, covered with grass, with boulders. From a diagnostic point of view, each image can be simultaneously viewed as a subject with, and with the object position. From the point of view of the object, an imaginary mountain - a representation of the most important for the patient objects. Mountains with acute apex associated primarily with the father-man's world, and a mountain with a rounded top - with maternal-feminine world. In this respect teens' mountain can be seen as a representation of the relationship to the 
mother.

In a review of panoramic view from the top of the mountain, the teenager saw the island on which was pointed (father) mountain, above that for which he climbed. On offer to climb the higher mountain, he refused, saying that it is impossible - it is too remote, too steep. From the way he came out with a sense of sadness. One can assume that by refusing to conquer the mountain, he could not identify with the father. This is confirmed by history, when he was about four years old, in front him between his parents there was a major scandal, during which the father hit his mother. This was a strong emotional shock for the child.

At the next class teenager was invited to present the image of a tree on a motive. He saw himself in a meadow in the middle of the island, which was on the last lesson. The island was a tree - Rowan, very branchy, but completely naked, without leaves. The tree gave the adolescent discomfort. From the way he came out again with a sense of longing. In the next lesson teenager said that the image of the island and a bare tree never left him, he always remembers them. Asked what this image means to him, he said that most likely, this is it, so lonely, nobody wanted on this island that cannot anybody make contact. We can assume that in this image is most clearly reflected the conflict situation of this period life teenagers - loneliness, longing, desire to retire, the desire to be left alone. After working with the motif of the tree has been a change in the drawings of the teenager. If the first pictures fit on a tenth of notebook sheet and were executed in pencil (a sign of the depressed state), after the tree motif pattern was most carefully drawn, and the entire paper was filled with colors.

In the next lesson teenager was proposed motif edge of the forest and the creature that emerges from the darkness of the forest. He saw the terrible, large, shaggy bear, which is a danger to him, could eat. Psychologist asked to feed the beast that the teenager was able to do. However, the proposal to establish friendly contact with the bear teenager flatly replied, "Oh, no." But after much persuasion, he agreed on the move. In the experience of the image can be assumed as a reflection of the problem situation of the moment at the object level - burdened relationships with parents, particularly his father; on subjection level - the rejection itself, some of their qualities.

In the next lesson teenager was offered a house motif. About burdened relationships with parents, particularly the mother, according to the experience of the image at home - the refusal to enter the teen room, and examine him.

We used the technique to study of teenager "three trees". This activity culminated in terms of relief from the pressure of parents. Work at this session was delayed and had to exceed the prescribed limit. First teen long and carefully loomed three trees (within 40 minutes). Trees teenager compared with dad, mom and older sister. Then the psychologist asked the teenager close your eyes, relax and imagine in your imagination to draw a tree. At present the image he wanted to sit next to these trees. On the question of the psychologist: "What else do you want to do?" The teenager replied flatly: "Escape". Left long in the wilderness, scorched by the sun. When he looked at the trees, he felt sad. But he went further in buoyant, good mood. He from the image of the teenager came out with a sense of deep satisfaction. In the final lesson, the teenager was offered a piece of land motif. He presented a huge island that bathes the sea. It was filled with joy, the mood was great. On the island at the teenager had his hut (which indicates the desire for autonomy), where he spent the night. In addition, he worked on the island blanks sports. On the question of the psychologist: "Who would want to invite to the island yet?". He wanted to call his girlfriend here and build a farm for personal use (which indicates the high claims concerning the establishment of the hearth). The image of the teenager felt autonomous, independent. After the image on the question of the psychologist: "How do you feel?", Replied, "Fine". After graduating classes at the teenager have been significant changes in behavior. He ceased to behave provocatively, build relationships with classmates at school, he stopped receiving comments from teachers, indicating that the development of autonomy and becoming mature "I". Using in the psycho correction work of symbol drama has shown to be highly effective.

\section{Discussion}

Thus, the study revealed that the level of aggression and anxiety correlated with the level of self-confidence and self-acceptance as follows.

Self-acceptance and level of self-confidence is low, as high level of aggression and anxiety. This is the kind of compensation. Adolescents with low self-esteem and low self-acceptance have no the skills to combat emerging contradictions of values and interests. It is difficult to solve the problem.

Help young people in addressing conflicts of personal development is to increase the level of self-esteem and self-acceptance. This is the most essential components of the formation of a harmoniously developed personality teenager. Invited to conduct trainings, and classes, individual counseling, exercise. We have held five training sessions. 
1) Removal of anxiety.

2) Dispersal of aggression.

3) The formation of self-esteem.

4) Development of self-confidence.

5) Update communication skills.

For $70 \%$ of adolescents were characterized by stable effect of psychological self-esteem and a positive change of self-acceptance. Decreased level of aggression and anxiety. Teens began to behave more confidently express their views directly and freely to participate in the formation of identity.

The optimal is art therapy and Gestalt techniques, which were carried out repeatedly. Drawings made by the participants of the first and second training, reflecting general trends of decreasing aggression and personality integration. When you study the projective techniques was revealed a positive trend, even in cases where the participant denied the existence of any significant changes.

\section{Conclusion}

Contradiction of the adolescent's personality depends on a many factors. This is physiological changes and social circumstances. Changing requirements of time may also cause the formation of contradictions value orientations. The orientation of life teenager is not known to the end yet. Its formation is associated with persistent stereotypes or little experience of life? These factors should be carefully studied. The teenagers must be investigated as a person. It concerns the social and psychological aspects in the context of modern society.

The contradictions between the needs of adolescents appear to find themselves and the difficulty of its implementation. Often obscene forms of verbal communication become a means to a fuller expression of their individuality. It is both a way to "psychological discharge" from the oppressive inferiority complex. The next study we believe the study types of complexes that occur in adolescence.

\section{References}

Baron, \& Richardson. (2000). Human Aggression. Moscow.

Bossart, A. B. (1991). Paradoxes of age or education. Moscow: Education.

Bozovic, L. I. (1968). Personality and its formation in childhood. Moscow: Educatio.

Dragunov, T. V. (1996). The crisis explained differently. Readings on the psychology. Moscow: Institute of Applied Psychology.

Dubrovin, I. V. (Ed.). (1991). Workbook school psychologist. Moscow.

Dubrovin, I. V. (Ed.). (1995). Psychological health of children and adolescents in the context of psychological services. Manual of Practical Psychology. Moscow.

Gippenreiter, Y. B. (1998). Introduction to general psychology. A course of lectures. Moscow: MSU.

Gluhanyuk, N. S., Dyachenko, E. V., \& Semenov, S. L. (2003). Workshop on general psychology. Textbook. Moscow - Voronezh.

Krylov, A. A. (1987). Workshop on general and experimental psychology (p. 256). Leningrad: Publisher Leningrad University.

Nemov, R. S. (2001). Psychology. In 3 books: Book2: Educational Psychology. Moscow

Nikolaenko, V. M. (Ed.). (1998). Personality Psychology. Novosibirsk. Psychological Service: kindergarten, school, college.

Obukhov, Y. L. (1995). Introduction to the basics symbol drama. Moscow.

Rogov, E. I. (1996). Handbook of Practical Psychology in education: A tutorial (p. 529). Moscow: VLADOS.

Rogov, E. I. (2001). Handbook of Practical psychology. Moscow.

Samoukina, N. V. (2002). Games at school and at home. Psycho-technical exercises and correctional programs. Moscow.

Sapagov, E. E. (2001). Psychology of Human Development: Textbook (pp. 1-274). Moscow: Aspekt Press.

Starovoytenko, E. B. (2001), Modern psychology. Moscow.

Tsirkin, S. Y. (Ed.) (2000). Handbook of psychology and psychiatry, child and adolescent. Moscow. 


\section{Copyrights}

Copyright for this article is retained by the author(s), with first publication rights granted to the journal.

This is an open-access article distributed under the terms and conditions of the Creative Commons Attribution license (http://creativecommons.org/licenses/by/3.0/). 